\title{
The Impacts of the Mass Rapid Transit System on Household Car Ownership in Taipei
}

\author{
Wen-Hsiu Huang ${ }^{1}$, Ming-Che Chao ${ }^{* 2}$ \\ ${ }^{1}$ Department of Public Finance, \\ Ling Tung University, Taichung, Taiwan \\ ${ }^{2}$ Institute of Civil Engineering, \\ National Chi Nan University, Nantou County, Taiwan \\ e-mail: dreame79.tw@yahoo.com.tw
}

Cite as: Huang, W. H., Chao, M. C., The Impacts of the Mass Rapid Transit System on Household Car Ownership in Taipei, J. sustain. dev. energy water environ. syst., 2(2), pp 191-207, 2014, DOI: http://dx.doi.org/10.13044/j.sdewes.2014.02.0016

\begin{abstract}
This paper investigates the impacts of Taipei Mass Rapid Transit (MRT) system on household car ownership and analyses how socioeconomic characteristics affect household car ownership. We employ a difference-in-difference (DID) strategy integrated with generalized Poisson regression models to examine the effects of MRT. The results are as follows: first, the establishment of Taipei MRT significantly reduced the level of household car ownership. Expanding the network of MRT system can be a feasible policy to control car ownership. Second, the levels of household car ownership are related to household's socioeconomic characteristics. Third, households with high dependence on public transport own fewer cars after Taipei MRT began operation. Hence, the traffic authority should adopt more effective methods to encourage public transit use in order to decrease household car ownership.
\end{abstract}

\section{KEYWORDS}

Mass Rapid Transit System, Car ownership, Household characteristics, Poisson regression, Generalized Poisson, Difference-in-difference

\section{INTRODUCTION}

In 1996, the mass rapid transit system was established in Taipei, becoming Taiwan's first and most developed MRT system. Taipei MRT is operated by the Taipei Rapid Transit Corporation. The number of passengers using Taipei MRT increased from 11 million persons in 1996 to 659 million persons in 2012. From 1996 to 2012, the average annual growth rate of MRT passengers was 37\%. In the same period, average car ownership per household exhibited a downward trend in Taipei and decreased from 0.56 in 1996 to 0.52 in 2012. The level of household car ownership in Taipei had a lower trend than that in the whole Taiwan. From 1996 to 2012, average car ownership per household had decreased by an annual rate of $0.04 \%$ in Taipei compared to an increase of $1.08 \%$ in the whole Taiwan. Thus, we are interested in the question that "Was the reduction of household car ownership attributed to Taipei MRT?" In this paper, we investigate whether Taipei MRT can effectively reduce household car ownership and how demographic and socioeconomic characteristics affect household car ownership. 
There are quantitative studies investigating the determinants of household vehicle ownership. The existing literature on vehicle ownership models can be divided into two kinds approaches. One body of studies has used macroeconomic analysis from aggregated and time series data. With the dynamic specification, this type of modelling can forecast the growth in vehicle ownership [1-3]. Moreover, energy demands and greenhouse gas emissions related to vehicle ownership can be projected [4, 5]. However, approaches based on aggregated data assume that individuals are homogeneous and do not examine the behavioural factors influencing different individuals. The other body of studies has employed microeconomic analysis from individual and cross-section data. Giuliano and Dargay (2006) used household-based surveys from the US and Great Britain to analyse the relationships between car ownership, daily travel and urban form [6]. Whelan (2007) used data from the family expenditure survey for modelling car ownership in Great Britain [7]. Matas and Raymond (2008) employed the Spanish Household Surveys to model car ownership [8]. In addition, a number of recent papers have utilized panel data combined longitudinal and cross-sectional data to estimate dynamic models of household car ownership [9-11]. Accordingly, households make important decisions on vehicle ownership and households are regarded as the basic units. The analysis using the household data can capture the heterogeneity of household characteristics and express the independence in decision making.

Previous studies have found that vehicle ownership decisions are related to various factors, including household income [8-10], households' socioeconomic characteristics $[7,11]$, residential location [13], public transport services $[8,12,14]$, the costs of vehicle ownership and use [3], and job accessibility [15]. Among these factors, public transport services play an important role in vehicle ownership decisions. Most studies demonstrate that a well-developed public transport network can decrease vehicle ownership. Cullinane (2002) indicated that good public transport can reduce vehicle ownership in the case of Hong Kong. He concluded that the existence of good public transport is one of the explanations of the low car ownership levels in Hong Kong [16]. Matas and Raymond (2008) found that car ownership is sensitive to the quality of public transport for those households living in the largest cities of Spain [8]. Chen and Lia (2011) suggested that motorcyclists' use intention with regard to public transport in Taipei (with well-developed public transport services) is higher than that in Kaohsiung (with under-developed public transport services). The effect of public transport development on reducing motorcycle usage is found to be significant [18].

However, some evidence shows that public transport policies are not always successful in alleviating the growth of vehicle ownership. Younes (1995) investigated the impact of major improvements to public transport in three major European cities. The results show that there may be some reductions in private vehicle use, but that these are only temporary and marginal [19]. Nagai et al. (2003) found that two-wheeled vehicle ownership tends to be suppressed by the presence of public transport in Bangkok and Chiang Mai, the two biggest cities of Thailand. However, there is no evidence that a good public transportation service can control two-wheeled vehicle ownership in other areas [14]. The study of Cullinane and Cullinane (2003) showed that despite the existence of excellent public transport in Hong Kong, once a car has been acquired, there is a tendency for it to be used [17]. Lai and Lu (2007) indicated that, in Asia, it is not easy to suppress the ownership levels of motorized vehicles by adopting price mechanism or by improving the quality of public transportation [20]. Chang and $\mathrm{Wu}$ (2008) explored vehicle dependence in Taipei, and the results show that even though mass public transit and bus services have been operated and intensively promoted, long-standing habits are still difficult to change in the motorcycle-dependent areas [21]. 
To examine the effects of Taipei MRT on household car ownership, we use the Poisson, generalized Poisson, and zero-inflated Poisson (ZIP) regression models. We employ a difference-in-difference (DID) strategy integrated with these models. We find that the generalized Poisson regression model is more appropriate than other two models. The empirical results are as follows. First, we verify that the establishment of Taipei MRT significantly reduced the level of household car ownership. Thus, expanding the network of MRT system can be a feasible policy to control car ownership. Second, the levels of household car ownership are related to households' demographic and socioeconomic characteristics. Third, the evidence shows that households with high dependence on public transport own fewer cars after the establishment of Taipei MRT. In other words, to encourage public transit use can decrease the level of household car ownership. The results can clarify the determinants of household car ownership and highlight the importance of the MRT system for transportation planning and energy sustainability.

The structure for the remainder of the paper is as follow. Section 2 describes the models and the identification strategy. Data description is also included in this section. Section 3 reports our empirical findings. Section 4 draws the conclusions and describes the policy implications of the results.

\section{METHODS AND DATA}

\section{Methods}

The Poisson, generalized Poisson, and zero-inflated Poisson regression model. In this paper, household car ownership decisions are modelled in three approaches: the Poisson regression model, generalized Poisson regression model and zero-inflated Poisson regression model. The Poisson regression is a standard framework used to analyse discrete counts. The standard Poisson probability function of household car ownership $\left(Y_{i}\right)$ can be written as follows:

$$
\begin{aligned}
& f_{i}\left(y_{i} ; \mu_{i}\right)=\frac{\mu_{i}^{y_{i}} \exp \left(-\mu_{i}\right)}{y_{i} !} \\
& y_{i}=0,1,2 \ldots
\end{aligned}
$$

where $i$ indexes households. The mean and variance of $Y_{i}$ are given by $E\left(Y_{i}\right)=\mu_{i}$ and $V\left(Y_{i}\right)=\mu_{i}$. The restrictive assumptions that the variance and mean of the count variable are equal may not be suitable to handle some types of count outcomes. In practice, the variance can either be larger or smaller than the mean. The phenomenon of excess variability is called over-dispersion, while the opposite phenomenon with the variance less than the mean is under-dispersion. The generalized Poisson regression model developed by Consul and Famoye (1992) and Famoye (1993) is more flexible and allows for over-dispersion or under-dispersion [22, 23]. The generalized Poisson probability function of household car ownership $\left(Y_{i}\right)$ can be expressed as the following:

$$
f_{i}\left(y_{i} ; \mu_{i}, \alpha\right)=\left(\frac{\mu_{i}}{1+\alpha \mu_{i}}\right)^{y_{i}} \frac{\left(1+\alpha y_{i}\right)^{y_{i}-1}}{y_{i} !} \exp \left(-\frac{\mu_{i}\left(1+\alpha y_{i}\right)}{1+\alpha \mu_{i}}\right)
$$

The mean and variance of $Y_{i}$ are given by $E\left(Y_{i}\right)=\mu_{i}$ and $V\left(Y_{i}\right)=\mu_{i}\left(1+\alpha \mu_{i}\right)^{2}$. The mean of the dependent variable is related to the explanatory variables through the link function: $\mu_{i}=\mu_{i}\left(x_{i}\right)=\exp \left(x_{i} \beta\right)$, where $x_{i}$ is a $(k-1)$ dimensional vector of explanatory 
variables and $\beta$ is a $k$-dimensional vector of regression parameters. The mean parameter $\mu_{i}$ can be modelled via $\log$ link function: $\log \left(\mu_{i}\right)=x_{i} \beta . \alpha$ is the dispersion parameter. When $\alpha$ equals zero, the probability function reduces to the Poisson probability function. For positive value of $\alpha$, it represents count data with over-dispersion. For negative value of $\alpha$, it represents count data with under-dispersion. To examine whether the generalized Poisson regression model is more suitable than the Poisson regression model, we can test the null hypothesis $H_{0}: \alpha=0$ using the asymptotic Wald $t$-statistic. When the null hypothesis is rejected, the use of generalized Poisson regression model can be supported. Alternatively, we can use the likelihood ratio test (LR test) to compare the fit of two models. The LR test statistics can be approximated using a chi-square distribution.

Another problem for count data is the presence of excess zeroes. The Poisson regression model which does not take account of many observed zeroes has the potential to result in biased coefficients and inaccurate stander errors. To accommodate the preponderance of zero count, we use the zero-inflated Poisson regression model proposed by Lambert (1992) [24]. The zero-inflated Poisson (ZIP) regression model includes two regressions: one predicting whether the count occurs and the other one predicting differences on the occurrence of the count. Consider a discrete random variable $Y_{i}$ with a zero-inflated Poisson distribution:

$$
f\left(y_{i} ; \mu_{i}, p_{i}\right)=\left\{\begin{array}{cll}
p_{i}+\left(1-p_{i}\right) \exp \left(-\mu_{i}\right) & \text { if } & y_{i}=0 \\
\left(1-p_{i}\right) \frac{\left(\mu_{i}\right)^{y_{i}} \exp \left(-\mu_{i}\right)}{y_{i} !} & \text { if } & y_{i}>0
\end{array}\right.
$$

The parameter $p_{i}$ specifies the probability of structural zero status, and $0<p_{i}<1$. The model incorporates extra zeroes than those allowed by the Poisson model. When $p_{i}=0$, the random variable $Y_{i}$ has a Poisson distribution. The mean and variance of the ZIP regression model are $E\left(Y_{i}\right)=(1-p) \mu_{i}$ and $\operatorname{Var}\left(Y_{i}\right)=(1-p) \mu_{i}\left(1+p \mu_{i}\right)$. The mean parameter $\mu_{i}$ is assumed to link to the covariates $x_{i}$ via a log-linear function: $\log \left(\mu_{i}\right)=x_{i} \beta . p_{i}$ can be modelled using a logit link function in which $\log p_{i} /\left(1-p_{i}\right)=z_{i} \gamma$, where $z_{i}$ is the $i^{\text {th }}$ row vector of the covariate matrix and $\gamma$ is the parameter vector. The covariates of $x_{i}$ and $z_{i}$ may or may not coincide. Although the ZIP model can solve the problem of preponderance of zeroes, there is no specific ratio of zero to nonzero counts used to determine if a particular distribution is zero-inflated. However, post hoc analyses can provide information to determine which model is the fittest one. To compare the ZIP and Poisson model, we can use the Vuong test which is based on a comparison of the predicted probabilities of two models that do not nest [25]. The test statistic is not asymptotically distributed standard normal. When the null hypothesis that the competing models are equally close to the true data generating process can be rejected, and it provides evidence of the superiority of the ZIP model over the Poisson model.

With regard to model selection between the generalized Poisson and ZIP regression models, the LR test described previously can be used. Furthermore, the Akaike information criterion (AIC) and Bayesian information criterion (BIC) can be used to measure the fit of models. The model with a lower information criterion is preferred.

Identification strategy: the difference-in-difference method. The purpose of this study is to identify the effects of Taipei MRT on household car ownership. We employ a 
difference-in-difference strategy that is integrated with the Poisson, generalized Poisson, and ZIP regression models. The DID method innovated by Ashenfelter and Card (1985) is used as an evaluation method to make causal inferences [26]. This method is widely applied to evaluate the impact of public policies. Ashenfelter and Card (1985) developed a DID methodology to estimate the effects of training programs on earnings [26]. Card and Krueger (1994) examined the impact of increase in New Jersey's minimum wage on employment in New Jersey's fast food restaurant [27]. Eissa and Liebman (1996) analysed how the labour force participation responds to the earned income credit [28]. Finkelstein (2002) investigated the impact of the tax subsidy to employer-provided health insurance on coverage by such insurance [29]. Hardoy and Schone (2010) studied the effect of a Norwegian family policy program on labour market participation [30]. Strumpf (2011) identified whether the public health insurance program affects on eligible women's labour force participation [31]. In the field of transport research, Li, et al. (2012) used the DID method to test the causal effect of the London congestion charge on road accidents [32].

However, the DID method has not been used to analyse public transport policies and vehicle ownership research. We employ the DID method in the analysis of public transport policies and embed this method in our models. Essentially, the DID method is based on comparing the difference between the two groups before and after the policy introduction. One group is the treatment group which is affected by the treatment in one period. The other group is the control group which is not affected by the treatment during both periods. Thus, a difference-in-differences estimator of the policy can be formed.

The key of the DID method is to select a proper control group. In Taiwan, Taipei and Kaohsiung are the two largest cities and have similar conditions in city development. However, the timing of MRT development in these two cities is different. Taipei MRT began operating in 1996, whereas the Kaohsiung MRT was established in 2007. There is no mass rapid transit system in Kaohsiung during the sample period. We can use the household data in Taipei as the treatment group and the household data in Kaohsiung as the control group. In order to provide a comparison between the changes in household car ownership affected by the MRT and the change in household car ownership not affected by the MRT, the sample period must cover the period before and after the establishment of Taipei MRT. Thus, the sample period is from 1986 to 2006 including the period before and after the MRT operation. However, the data in 1996 are excluded because the MRT effect is ambiguous in the first year of operation. In other words, we compare the change in household car ownership from a before to an after-period for similar areas (Taipei and Kaohsiung) in different time periods (1986-1995 versus 1997-2006).

Based on the generalized linear models for count data discussed previously, the DID model can be written as follows:

$$
\ln \mu_{i t}=\beta_{1}+\beta_{2} m r t_{i t}+\beta_{3} \operatorname{area}_{i t}+\beta_{4}\left(m r t_{i t} \times \operatorname{area}_{i t}\right)+\gamma X_{i t}+\varepsilon_{i t}
$$

where $i$ indexes households, and $t$ indexes time $(1=$ the post-treatment period; $0=$ the pre-treatment period). $m r t_{i t}$ is the time-specific component, which is a dummy variable valued at 1 if the period is 1997 to 2006 (after the establishment of Taipei MRT) and 0 if the period is 1986 to 1995 (before the establishment of Taipei MRT). area $_{i t}$ is a group-specific component, which is a dummy variable valued at 1 if the household is in Taipei, and 0 if the household is in Kaohsiung. $m r t_{i t} \times a r e a_{i t}$ is an interaction term which 
indicates a treated household after the policy. $X_{i t}$ is the vector of covariates uncorrelated with the error term $\varepsilon_{i t}$, and $\gamma$ is the vector of coefficients. $\beta_{1}$ is the constant term, $\beta_{2}$ controls for changes in household car ownership between the before and after the establishment of Taipei MRT, $\beta_{3}$ controls for effects of treatment group, and $\beta_{4}$ captures the treatment effect we are interested in. The marginal effects of covariates can be interpreted via the estimated incidence rate ratio, which can be obtained from the exponentiated coefficients.

The DID estimator is the difference in average outcome in treatment group before and after the treatment minus the difference in average outcome in control group before and after the treatment. The DID estimator can be presented as follows:

$$
\begin{gathered}
\text { DID estimator }=\hat{\beta}_{4}=\left(\bar{Y}_{1 T}-\bar{Y}_{0 T}\right)-\left(\bar{Y}_{1 C}-\bar{Y}_{0 C}\right) \\
E\left(\hat{\beta}_{4}\right)=\left(\beta_{1}+\beta_{2}+\beta_{3}+\beta_{4}\right)-\left(\beta_{1}+\beta_{3}\right)-\left(\beta_{1}+\beta_{2}\right)+\beta_{1}=\beta_{4}
\end{gathered}
$$

In Eq. 5, the first bracket, $\left(\bar{Y}_{1 T}-\bar{Y}_{0 T}\right)$, measures the change in household car ownership of the treatment group between the before and after period. The second bracket, $\left(\bar{Y}_{1 C}-\bar{Y}_{0 C}\right)$, measures the change in household car ownership of the control group between the before and after period. As shown in Eq. 6, the DID estimator is an unbiased estimator. If Taipei MRT is effective to reduce household car ownership, the sign of the DID estimator should be negative.

The conventional DID method is based on the strong assumption that the average outcomes for the treated and control groups would have followed parallel paths over time in the absence of the treatment. In practice, this assumption is implausible if the treatment and control groups are unbalanced in covariates that are associated with the dynamics of the outcome variable. To consider this problem, a vector of covariates $X$ can be introduced to the DID model to capture compositional differences between the treatment and control groups $[32,33]$. The use of covariates can describe how the average effect of the treatment varies with changes in observed characteristics and represent heterogeneity in outcome dynamic. In addition, the effect of the treatment is allowed to differ among individuals.

\section{Data}

The household data is based on Taiwan's Family Income and Expenditure Survey (FIES) from 1986 to 2006 including the period before and after the establishment of Taipei MRT. The FIES is a nationwide cross-sectional survey which has been conducted annually by the Taiwanese government since 1964 . There are about 14,000 households sampled independently each year, but households are not tracked. This database collects household characteristics and demographic information, property and facilities, income, and expenditures.

In this paper, we focus on how Taipei MRT affects household car ownership. We restrict our observations to households in the two biggest cities in Taiwan: Taipei and Kaohsiung. Taipei locates in the north of Taiwan, and Kaohsiung locates in the south. We use Taipei households which are affected by Taipei MRT as the treatment group (area=1) and Kaohsiung households which are not affected by Taipei MRT as the control group $($ area $=0)$. $m r t$ is a dummy variable equal to 1 for the period of 1986-1995, and 0 for the 
period of 1997-2006. We exclude the data for 1996, the year that Taipei MRT began operation, because the effect of Taipei MRT on household car ownership was unclear. The full sample comprises 72800 households. The DID method does not require the treatment and control groups to have the same demographic characteristics. Although these two cities are similar in city development, other factors may lead to differences in household car ownership between the treatment and control groups [33]. Therefore, we use household head characteristics and household characteristics as the independent variables.

A household head is defined as the main earner or economic supporter in the household. Household head characteristics contain age (age), educational attainment $(e d u)$, gender (gender), whether or not an employee (emp), and whether or not participate in the labour market (work). Education level is an ordinal variable with four categories, including primary school, high school, college or university, and graduated school. We assign scores 1, 2, 3 and 4 to these four levels. Gender is measured by a dummy variable, taking the value 1 if the household head is male and 0 otherwise. Whether a household head is an employee is measured by a dummy variable, taking the value 1 if a household head is an employee and 0 otherwise. This variable is intended to capture the difference of employment status that an employer with better economic ability and higher socioeconomic status may incline to own a car. Labour market participation is a dummy variable, taking the value 1 if a household head participates in the labour market and 0 otherwise. This variable can capture mobility needs of households [34].

Household characteristics consist of household size (size), household income (income), the number of parking lots (park), and the number of motorcycles per household (moto). The variable of household size is involved. We expected the sign of this parameter to be positive, highlighting the need for vehicles as the number of household members increase. Household income is an important factor in the vehicle demand function. Whether household decide to buy vehicles or not and what kind of vehicles they choose are economic decisions. Many studies have verified that car ownership is related to the economic ability of households $[10,35]$. In this study, we use disposable income to measure the economic ability of households. The household disposable income variables are deflated using the Consumer Price Index, whose base year is 1996. The number of parking lots self-owned by a household is included in the model because easy car parking may be also a key point for households to own cars. In an alternative specification, we consider the number of motorcycles per household as an explanatory variable, since there may exist an unknown relationship between car ownership level and motorcycle ownership level. The relationship may be positive if there is a complementary effect, and negative if there is a substitution effect.

Table 1 presents descriptive statistics of the variables for the treatment and control groups in the pre-treatment and post-treatment years. The mean values for the continuous variables and ratios for the categorical variables are reported. The average number of cars per household in Taipei before and after the treatment is less than that in Kaohsiung. If we compare the count data in the two periods, the level of household car ownership increases 0.06 (from 0.57 to 0.63 ) in Kaohsiung during the study period, whereas it increases 0.04 (from 0.42 to 0.46 ) in Taipei.

Moreover, Figure 1 shows that the level of household car ownership in Taipei rises more slowly than that in Kaohsiung. This difference exhibits the possibility that household car ownership in Taipei may reduce due to the operation of Taipei MRT. This conjecture should be examined after other covariates which may lead to the difference between the treatment and control groups were taken into account. The descriptive statistics show that household heads in the treatment group are younger, had higher 
education level, and are with a higher proportion of males and employees. Besides, households in the treatment group owned fewer motorcycles and had higher income. We control for differences in observable characteristics so as to increase confidence in the empirical results.

We observe that the variance of household car ownership is smaller than the mean for the treatment and control groups. This phenomenon reveals that we should employ the generalized Poisson model to estimate. Besides, we should take note of the presence of excess zeroes in the sample. The ratios of zero counts are high in the pre-treatment period: $60.31 \%$ in Taipei, and $59.80 \%$ in Kaohsiung. Thus, this phenomenon implies that the ZIP model should also be considered.

Table 1. Descriptive statistics for treatment and control groups

\begin{tabular}{|c|c|c|c|c|}
\hline \multirow[b]{2}{*}{ Variables } & \multicolumn{2}{|c|}{ Taipei (Treatment group) } & \multicolumn{2}{|c|}{ Kaohsiung (Control group) } \\
\hline & $\begin{array}{c}1986-1995 \\
\text { (Pre-treatment) }\end{array}$ & $\begin{array}{c}1997-2006 \\
\text { (Post-treatment) }\end{array}$ & $\begin{array}{c}1986-1995 \\
\text { (Pre-treatment) }\end{array}$ & $\begin{array}{c}1997-2006 \\
\text { (Post-treatment) }\end{array}$ \\
\hline \multicolumn{5}{|l|}{ Dependent variable } \\
\hline Number of cars per household & $0.42(0.29)$ & $0.57(0.34)$ & $0.46(0.39)$ & $0.63(0.39)$ \\
\hline Zero value [\%] & $60.31 \%$ & $47.41 \%$ & $59.80 \%$ & $43.89 \%$ \\
\hline Non-zero value [\%] & $39.69 \%$ & $52.59 \%$ & $40.20 \%$ & $56.11 \%$ \\
\hline \multicolumn{5}{|l|}{ Independent variable } \\
\hline \multicolumn{5}{|l|}{ Household head characteristics: } \\
\hline Age (years) & 44.68 & 48.15 & 45.89 & 47.17 \\
\hline Educational attainment (average level) & 2.13 & 2.36 & 1.78 & 2.10 \\
\hline Level 1- Primary school [\%] & 24.72 & 16.26 & 41.58 & 22.72 \\
\hline Level 2- High school [\%] & 39.77 & 37.93 & 39.57 & 47.11 \\
\hline Level 3- University [\%] & 33.04 & 39.15 & 18.15 & 27.74 \\
\hline Level 4- Graduate school [\%] & 2.47 & 6.66 & 0.70 & 2.43 \\
\hline Male $[\%]$ & 78.60 & 75.80 & 77.56 & 75.68 \\
\hline Employee $[\%]$ & 59.66 & 62.78 & 56.38 & 60.29 \\
\hline Participating in labour market [\%] & 79.84 & 80.58 & 74.40 & 80.63 \\
\hline \multicolumn{5}{|l|}{ Household characteristics: } \\
\hline Household size (persons) & 4.02 & 3.49 & 4.10 & 3.48 \\
\hline Household income (in NT $\$ 100,000$ ) & 8.62 & 14.90 & 7.10 & 11.39 \\
\hline Number of parking lots & 0.79 & 0.10 & 0.79 & 0.17 \\
\hline Number of motorcycles per household & 0.61 & 0.84 & 1.43 & 1.61 \\
\hline Number of observations & 25000 & 22000 & 12000 & 13800 \\
\hline
\end{tabular}

Notes: Table reports the mean values and ratios. The values in the parentheses in the second row are variances.

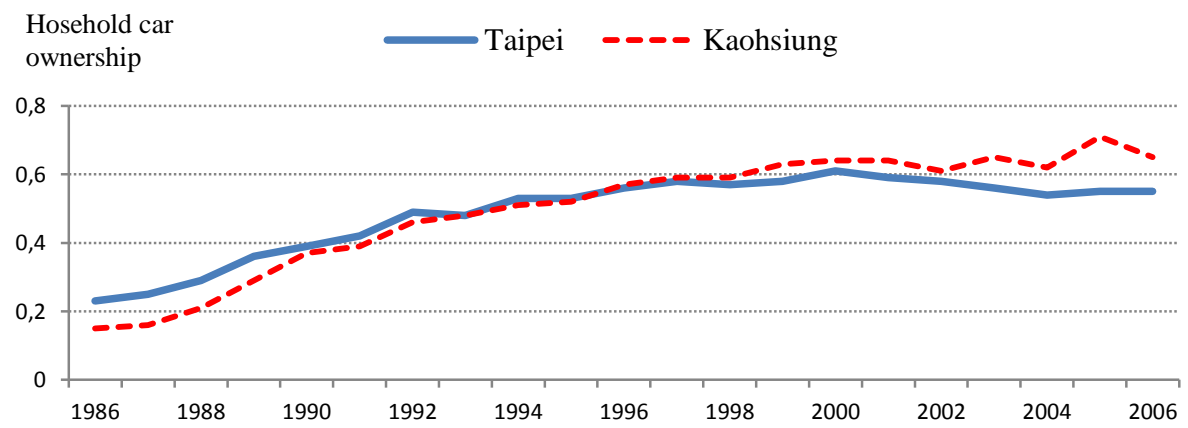

Figure 1. The trends of household car ownership in Taipei and Kaohsiung 


\section{EMPIRICAL RESULTS}

We employ the Poisson regression model (Model 1), generalized Poisson regression model (Model 2), and ZIP regression model (Model 3) to investigate whether the Taipei MRT can reduce household car ownership. We use the DID method as the identification strategy in these three models. All regression analyses were conducted in Stata version 12.0 .

\section{Model selection}

Table 2 reports the results of estimation and testing for the Poisson, generalized Poisson, and ZIP regression models. Model selection is an important part of the statistical analysis. In the Poisson regression model, the Pearson dispersion statistic and the Deviance dispersion statistic can offer us information to judge whether the Poisson model is appropriate. ${ }^{1}$ If there is no over-dispersion or under-dispersion, the statistic will be close to 1 . The data may be under-dispersion if the statistic is less than 1 and over-dispersion if the statistic is greater than 1 [36]. Our results show that the Pearson dispersion statistic is 0.6839 , and the Deviance dispersion statistic is 0.6846 . This result implies the data is under-dispersion.

Table 2. Results of Poisson, Generalized Poisson and ZIP regression model

\begin{tabular}{|c|c|c|c|c|c|c|c|c|}
\hline \multirow{3}{*}{ Variables } & \multirow{2}{*}{\multicolumn{2}{|c|}{$\begin{array}{l}\text { Poisson } \\
\text { (Model 1) }\end{array}$}} & \multirow{2}{*}{\multicolumn{2}{|c|}{$\begin{array}{l}\text { Generalized Poisson } \\
\text { (Model 2) }\end{array}$}} & \multicolumn{4}{|c|}{$\begin{array}{c}\text { ZIP } \\
\text { (Model 3) }\end{array}$} \\
\hline & & & & & \multicolumn{2}{|c|}{ Continuous outcome } & \multicolumn{2}{|c|}{ Dichotomous outcome } \\
\hline & Coefficient & $\begin{array}{c}\text { Standard } \\
\text { Error }\end{array}$ & Coefficient & $\begin{array}{l}\text { Standard } \\
\text { Error }\end{array}$ & Coefficient & $\begin{array}{l}\text { Standard } \\
\text { Error }\end{array}$ & Coefficient & $\begin{array}{c}\text { Standard } \\
\text { Error }\end{array}$ \\
\hline Constant & $-1.9648 * *$ & 0.0431 & $-1.5337 * *$ & 0.0355 & $-1.3529 * *$ & 0.0499 & $1.5722 * *$ & 0.3117 \\
\hline age & $-0.0082 * *$ & 0.0005 & $-0.0074 * *$ & 0.0004 & $-0.0048 * *$ & 0.0006 & $0.0495 * *$ & 0.0037 \\
\hline gender & $0.1207 * *$ & 0.0143 & $0.0251 *$ & 0.0116 & $0.0756^{* *}$ & 0.0161 & $-0.8277^{* *}$ & 0.0863 \\
\hline emp & $-0.0796 * *$ & 0.0134 & $-0.0282 * *$ & 0.0099 & $-0.0354 *$ & 0.0144 & $0.4942 * *$ & 0.0939 \\
\hline work & $0.2472 * *$ & 0.0214 & $0.0654 * *$ & 0.0125 & $0.0807 * *$ & 0.0238 & $-0.2952 *$ & 0.1183 \\
\hline$e d u$ & $0.2256^{* *}$ & 0.0073 & $0.1751 * *$ & 0.0065 & $0.1343 * *$ & 0.0083 & $-0.1157^{*}$ & 0.0548 \\
\hline size & $0.1311 * *$ & 0.0036 & $0.1133 * *$ & 0.0023 & $0.0764 * *$ & 0.0043 & $-0.0630 *$ & 0.0299 \\
\hline park & $0.2410 * *$ & 0.0123 & $0.2677 * *$ & 0.0101 & $0.2555^{* *}$ & 0.0125 & $-1.2631 * *$ & 0.1057 \\
\hline income & $0.0177^{* *}$ & 0.0003 & $0.0198 * *$ & 0.0002 & $0.0149 * *$ & 0.0004 & $-0.8409^{* *}$ & 0.0239 \\
\hline area & $-0.2077 * *$ & 0.0168 & $-0.2730 * *$ & 0.0091 & $-0.1853 * *$ & 0.0196 & $0.8092 * *$ & 0.1040 \\
\hline area $\times m r t$ & -0.0013 & 0.0218 & $-0.0586^{* *}$ & 0.0162 & $-0.0067^{*}$ & 0.0024 & $0.6648^{* *}$ & 0.1516 \\
\hline$m r t$ & $0.3389 * *$ & 0.0192 & $0.1820 * *$ & 0.0156 & $0.3246^{* *}$ & 0.0209 & $-0.3917^{* *}$ & 0.1438 \\
\hline $\begin{array}{c}\text { Dispersion } \\
\text { parameter }\end{array}$ & & & $-0.1034 * *$ & 0.0010 & & & & \\
\hline $\begin{array}{c}\text { Log } \\
\text { likelihood }\end{array}$ & \multicolumn{2}{|c|}{-59918.58} & \multicolumn{2}{|c|}{-57852.01} & \multicolumn{4}{|c|}{-58492.90} \\
\hline LR chi2 & \multicolumn{2}{|c|}{$9294.83^{* *}$} & \multicolumn{2}{|c|}{$9368.47 * *$} & \multicolumn{4}{|c|}{$3112.93^{* *}$} \\
\hline AIC & \multicolumn{2}{|c|}{119861} & \multicolumn{2}{|c|}{115730} & \multicolumn{4}{|c|}{117034} \\
\hline BIC & \multicolumn{2}{|c|}{119972} & \multicolumn{2}{|c|}{115850} & \multicolumn{4}{|c|}{117255} \\
\hline Pseudo R2 & \multicolumn{2}{|c|}{0.0720} & \multicolumn{2}{|c|}{0.0940} & \multicolumn{4}{|c|}{0.0749} \\
\hline
\end{tabular}

Notes: $1 . *$ and $* *$ represent $5 \%$ and $1 \%$ significance level, respectively.

2. LR chi2 is the LR chi-square test that at least one of the predictors' regression coefficients is not equal to zero in the model.

\footnotetext{
${ }^{1}$ The Pearson dispersion statistic is measured by the Pearson's chi-square divided by the degree of freedom. The Deviance dispersion statistic is measured by the deviance chi-square divided by the degree of freedom.
} 
In addition, we employ the generalized Poisson regression model to estimate. The estimated dispersion parameter from the generalized Poisson regression model is -0.1034 . The asymptotic $t$-statistic for test the null hypothesis of $\alpha=0$ is 99.39 . At the $1 \%$ significant level, the null hypothesis $\alpha=0$ is rejected. Thus, we confirm that the outcome variable is under-dispersion. Therefore, these results indicate that the generalized Poisson regression model is preferred to the Poisson regression model.

Additionally, the ZIP model which accounts for the excess zeroes by predicting a dichotomous outcome and a continuous outcome was estimated. To compare the ZIP model to the standard Poisson model, we use the Vuong test testing for the null hypothesis that both models are equally similar to the observed distribution [25]. The results show that $z$-value is 20.61 and significant at the $1 \%$ significant level. Therefore, the ZIP regression is preferred to the Poisson regression model. As shown in Table 2, the parameter estimates from the Poisson, generalized Poisson, and ZIP regression model are similar and consistent. However, because the Poisson model does not account for the under-dispersion, the standard errors from the Poisson model are over-estimated. Thus, the $t$-values of regression parameters are generally downward biased for the Poisson model.

Both the generalized Poisson and the ZIP regression model are preferred to the Poisson regression model, and then we can compare the generalized Poisson regression model to the ZIP regression model using the LR test. The results show that, at the $1 \%$ significant level, the null hypothesis that the generalized Poisson regression model is nested in the ZIP regression model cannot be rejected. Thus, the generalized Poisson model is more appropriate than the ZIP model. In addition, the goodness-of-fit measures, such as AIC and BIC, also indicate that the generalized Poisson regression fits better than other two models.

\section{The responses of household car ownership}

Since the adequacy of the generalized Poisson regression over other two models was confirmed, the following interpretation of predictors would be based on the generalized Poisson regression. First, as shown in Table 2, we focus on the variables specified by the DID method. The coefficient of area captures unobserved differences related to household car ownership between households in Taipei and Kaohsiung. We find that the coefficient of area is significantly negative. Thus, Taipei households tend to own fewer cars than Kaohsiung households. This result may be related to the high population density and limited parking spaces in Taipei. In addition, the coefficient of $m r t$ is significantly positive. Therefore, the level of household car ownership in Taipei and Kaohsiung has an increase in the second period compared to the first period. This result is consistent with the information that data description discloses. As for the treatment effect we are interested in, we find that the coefficient of area $\times m r t$ is significantly negative at the $1 \%$ significant level, suggesting that Taipei MRT can reduce household car ownership. This result is consistent with the findings of Cullinane (2002) and Matas and Raymond (2008), suggesting that the improvement of public transit system can decrease the number of car ownership $[8,16]$.

The strong increase in Taipei MRT use reflects the effectiveness of Taipei MRT. The extension of Taipei MRT along with multiple bus lines constructs a well-developed public transport network and makes urban transport time-saving, efficient and clean. From 1996 to 2012, the average annual growth rate for the passenger-kilometres travelled and the number of passengers are $37 \%$ and $46 \%$, respectively. Taipei MRT offers people safety, comfortable, and time-saving services. When people's income increases, they will prioritize the quality of transit services. Therefore, the MRT system attracts those people 
who can afford to the MRT fare. Furthermore, the Taipei MRT agency offers some discount policies for passengers. For example, passengers who transfer from the MRT to bus or vice versa within one hour will receive a discount. Cullinane (2002) suggested that good and cheap public transport services are vital to the effective provision of public transport [16]. Redman et al. (2013) indicated that the quality attributes of reliability and frequency are most important in determining general public transport demand, while accessibility, reliability, and mobility attributes of public transport services are most attractive to car users [37]. Thus, improving the quality of public transport services with a reasonable fare may not only encourage the use of public transport but also decrease the use of cars.

Second, we look at the coefficients of household head characteristics. At the 5\% significance level, the coefficients of age and emp are significantly negative, whereas the coefficients of gender, work, and $e d u$ are significantly positive. These results suggest that households with older household heads own fewer cars than those with younger household heads. Household heads who are employees own fewer cars than those who are employers. We also find that there exists gender difference in household car ownership. Male-headed households incline to have more cars than female-headed households. Household heads with a job have more cars than household heads without a job. Moreover, the number of household car ownership will increase with education level of household heads.

Third, we observe the coefficients of household characteristics. The coefficients of size, park, and income are significantly positive at the $1 \%$ significance level. The result indicates that household car ownership will increase with the number of household members. The positive effect of household size on the level of car ownership is consistent with the results of Dargay (2002) [10]. In addition, the results show that the number of self-owned parking lots has positive effects on the level of car ownership. Because of population growth in Taipei and Kaohsiung, the number of self-owned parking lots exhibits a downward trend. For example, in Taipei, the number of self-owned parking lots reduces from 0.79 during the period of 1986-1995 to 0.10 during the period of 1997-2006. The decrease of parking lots owned by households may be related to slow growth in household car ownership level.

It is worth noting that the level of household income is positively related with household car ownership. The positive income effect on car ownership also has been evidenced by previous research, such as Dargay and Gately (1999) [2], Dargay (2001) [7], Dargay (2002) [10], and Dissanayake and Morikawa (2010) [12]. However, Jou et al. (2012) find that the long-run relationship between household income and car ownership exists for Kaohsiung but not for Taipei [35]. They suggest that driving car in Taipei is not convenient because of high population density, heavy traffic, and the well-developed public transport system in Taipei. In Kaohsiung, the significantly positive effects of household income on car ownership can be attributed to the poor public transit and easy car parking. Therefore, our results obtained from cross-section data can be regarded as a complement to the findings of Jou et al. (2012) obtained from time series data. Our results verify that households will own more cars if their economic ability improve, but Taipei MRT can prevent the growth in car ownership level. Therefore, we can draw the same conclusion that the well-developed public transport system in Taipei can serve as a way to decouple household income and car ownership.

\section{Alternative specifications}

To improve the reliability of policy effect, we estimate the generalized Poisson model with alternative specifications. Results of alternative specifications for the generalized 
Poisson regression model are reported in Table 3. Model 4 considers the year fixed effects. Model 5 incorporates the level of motorcycle ownership into the model. Model 6 includes the effect of public transportation use interaction.

Table 3. Results of alternative specifications

\begin{tabular}{|c|c|c|c|c|c|c|}
\hline \multirow[t]{2}{*}{ Variables } & \multicolumn{2}{|c|}{$\begin{array}{l}\text { With the year fixed effects } \\
\text { (Model 4) }\end{array}$} & \multicolumn{2}{|c|}{$\begin{array}{l}\text { With motorcycle ownership } \\
\text { (Model 5) }\end{array}$} & \multicolumn{2}{|c|}{$\begin{array}{c}\text { With public transportation use } \\
\text { interaction } \\
\text { (Model 6) }\end{array}$} \\
\hline & Coefficient & $\begin{array}{l}\text { Standard } \\
\text { Error }\end{array}$ & Coefficient & $\begin{array}{l}\text { Standard } \\
\text { Error }\end{array}$ & Coefficient & $\begin{array}{l}\text { Standard } \\
\text { Error }\end{array}$ \\
\hline Constant & $-1.5917^{* *}$ & 0.0326 & $-1.6622 * *$ & 0.0321 & $-1.6957 * *$ & 0.0328 \\
\hline age & $-0.0097 * *$ & 0.0004 & $-0.0089 * *$ & 0.0004 & $-0.0085^{* *}$ & 0.0004 \\
\hline gender & $0.0153 *$ & 0.0072 & $0.0145^{*}$ & 0.0070 & $0.0151 *$ & 0.0070 \\
\hline emp & $-0.0359^{* *}$ & 0.0109 & $-0.0406^{* *}$ & 0.0108 & $-0.0519 * *$ & 0.0110 \\
\hline work & $0.0465^{* *}$ & 0.0151 & $0.0343^{*}$ & 0.0152 & $0.0341 *$ & 0.0151 \\
\hline$e d u$ & $0.1132 * *$ & 0.0064 & $0.1221 * *$ & 0.0064 & $0.1233^{* *}$ & 0.0065 \\
\hline size & $0.1204 * *$ & 0.0027 & $0.1073 * *$ & 0.0029 & $0.1077 * *$ & 0.0030 \\
\hline park & $0.2985^{* *}$ & 0.0118 & $0.3282 * *$ & 0.0121 & $0.3252 * *$ & 0.0121 \\
\hline income & $0.0201 * *$ & 0.0003 & $0.0201 * *$ & 0.0003 & $0.0202 * *$ & 0.0003 \\
\hline area & $-0.1503 * *$ & 0.0123 & $-0.1034 * *$ & 0.0126 & $-0.1096 * *$ & 0.0129 \\
\hline area $\times m r t$ & $-0.0360 *$ & 0.0172 & $-0.0352 *$ & 0.0172 & $-0.0350 *$ & 0.0170 \\
\hline$d 1987$ & $-0.1013 *$ & 0.0188 & $-0.1064 * *$ & 0.0217 & $-0.0937 * *$ & 0.0219 \\
\hline$d 1988$ & $0.7798 * *$ & 0.0177 & $0.6960 * *$ & 0.0215 & $0.7047 * *$ & 0.0218 \\
\hline d1989 & $-0.0605 * *$ & 0.0168 & $-0.0907 * *$ & 0.0171 & $-0.0970 * *$ & 0.0179 \\
\hline d1990 & $0.4622 * *$ & 0.0187 & $0.4301 * *$ & 0.0187 & $0.4282 * *$ & 0.0188 \\
\hline$d 1991$ & -0.0325 & 0.0229 & -0.0137 & 0.0215 & -0.0117 & 0.0230 \\
\hline d1992 & $0.2382 * *$ & 0.0195 & $0.1744 * *$ & 0.0207 & $0.1746^{* *}$ & 0.0209 \\
\hline d1993 & $0.1317 * *$ & 0.0267 & $0.0703 * *$ & 0.0269 & $0.0779 * *$ & 0.0274 \\
\hline d1994 & $0.4656^{* *}$ & 0.0278 & $0.4502 * *$ & 0.0230 & $0.4465^{* *}$ & 0.0246 \\
\hline$d 1995$ & $0.4897 * *$ & 0.0293 & $0.4492 * *$ & 0.0294 & $0.4538 * *$ & 0.0298 \\
\hline$d 1997$ & $0.5916^{* *}$ & 0.0288 & $0.5283 * *$ & 0.0287 & $0.5245^{* *}$ & 0.0294 \\
\hline d1998 & $0.5624 * *$ & 0.0288 & $0.5019 * *$ & 0.0289 & $0.5011 * *$ & 0.0295 \\
\hline d1999 & $0.6383 * *$ & 0.0236 & $0.6059 * *$ & 0.0236 & $0.6497 * *$ & 0.0241 \\
\hline$d 2000$ & $0.5827 * *$ & 0.0283 & $0.5184 * *$ & 0.0284 & $0.5165^{* *}$ & 0.0288 \\
\hline$d 2001$ & $0.5019 * *$ & 0.0287 & $0.4332 * *$ & 0.0291 & $0.4296^{* *}$ & 0.0296 \\
\hline$d 2002$ & $0.5328 * *$ & 0.0289 & $0.4657 * *$ & 0.0291 & $0.4605^{* *}$ & 0.0294 \\
\hline$d 2003$ & $0.5691 * *$ & 0.0285 & $0.5004 * *$ & 0.0286 & $0.4989 * *$ & 0.0293 \\
\hline$d 2004$ & $0.5484 * *$ & 0.0288 & $0.4730 * *$ & 0.0291 & $0.4723 * *$ & 0.0295 \\
\hline$d 2005$ & $0.6089 * *$ & 0.0265 & $0.5254 * *$ & 0.0281 & $0.5246^{* *}$ & 0.0286 \\
\hline$d 2006$ & $0.5649 * *$ & 0.0284 & $0.4879 * *$ & 0.0284 & $04865^{* *}$ & 0.0291 \\
\hline moto & - & - & $0.0645^{* *}$ & 0.0047 & $0.0612 * *$ & 0.0047 \\
\hline Fxareaxmrt & - & - & - & - & $-0.1613^{* *}$ & 0.0157 \\
\hline $\begin{array}{l}\text { Dispersion } \\
\text { parameter }\end{array}$ & $-0.1517^{* *}$ & 0.0019 & $-0.1522 * *$ & 0.0019 & $-0.1501 * *$ & 0.0019 \\
\hline $\begin{array}{c}\text { Log } \\
\text { likelihood }\end{array}$ & \multicolumn{2}{|c|}{-56162.22} & \multicolumn{2}{|c|}{-56061.96} & \multicolumn{2}{|c|}{-56008.78} \\
\hline LR chi2 & \multicolumn{2}{|c|}{$12748.04 * *$} & \multicolumn{2}{|c|}{$12948.57 * *$} & \multicolumn{2}{|c|}{$13054.92 * *$} \\
\hline AIC & \multicolumn{2}{|c|}{112386} & \multicolumn{2}{|c|}{112188} & \multicolumn{2}{|c|}{112084} \\
\hline $\mathrm{BIC}$ & \multicolumn{2}{|c|}{112672} & \multicolumn{2}{|c|}{112482} & \multicolumn{2}{|c|}{112387} \\
\hline Pseudo R2 & \multicolumn{2}{|c|}{0.1019} & \multicolumn{2}{|c|}{0.1035} & \multicolumn{2}{|c|}{0.1044} \\
\hline
\end{tabular}


In the model 4, we account for the specific time effects because the data is collected from different years. To control for the year fixed effects, the dummy variables for each data year are included [38]. The omitted year is 1986. In this type of specification, we replace the variable $m r t$ with these dummy variables for each year. As shown in Table 3, all the year dummy variables are significant in Model 4, except the year 1991. Moreover, we use the LR test to examine whether Model 4 is more appropriate than Model 2. The statistics of LR chi-square with 18 degrees of freedom is 3379.57 and significant. This result supports that the specification of using the dummy variables for each year can improve the fitness of model. In term of the effect of Taipei MRT, we find that the coefficient of area $\times M R T$ is negative and significant at the $1 \%$ significance level. Therefore, the hypothesis that the level of household car ownership decreases after the establishment still can be confirmed. In addition, the results of other variables are consistent with those in Model 2.

In the Model 5, we further include the variable of motorcycle ownership in the model since motorcycles and public transport are the alternate modes that car drivers could switch to. The literature shows that motorcycle usage in Taipei has been still experiencing continuing growth, even the service quality of public service has been improved [20,21]. The relatively slow growth in the level of household car ownership in Taipei may be due to the upward trend of motorcycle ownership level. Therefore, we try to control for the level of household motorcycle ownership in the model. The results of Model 5 indicate that the coefficient of moto is positive and significant at the $1 \%$ significance level. This result rejects the conjecture that motorcycle ownership may be substitute for car ownership. In fact, the relationship between the level of motorcycle and car ownership will be determined by the income effect and substitution effect. The growth of private vehicle ownerships is associated with the increase in the income levels. However, once the income level grows up to a certain level, people will shift from motorcycle to car ownerships for their prestige, convenience, comfort and safety [5]. Therefore, the positive relationship between motorcycle and car ownership may be due to the income effect dominate the substitution effect. The LR test is used to compare the fit of model 4 and model 5 . The statistics of LR chi-square with 1 degree of freedom is 200.53 and significant. This result confirms that Model 5 is better than Model 4. As for the treatment effect, the coefficient of area $\times m r t$ is significantly negative. Consequently, the negative impact of Taipei MRT on the number of household car ownership is consistent with the finding of previous specification.

The Taipei MRT system has contributed to the improvement of public transport network. The expansion of public transport network can induce car drivers to use public transport. Furthermore, the traffic authorities have enacted many policies to encourage people to use public transportation, such as discounts on public transportation fares, transfer information provision, and increasing car parking fees. However, the increase in public transport use does not mean that the level of car ownership will decrease. To explore whether car users really switch to public transport and own fewer cars after the establishment of Taipei MRT, we add an interaction term $F \times$ area $\times m r t$ in the model, which is denoted as Model 6 . The new dummy variable, $F$, equals to 1 if the household is relatively high dependence on public transport and 0 otherwise. We define households with high dependence on public transport as the top 50\% households ranked by households' public transportation expenditure. This specification can examine whether households with high dependence on public transport really reduce the level of car ownership. As shown in Table 3, the coefficient of $F \times$ area $\times$ mrt is negative and significant at the $1 \%$ significance level. This result verifies that households with high dependence on public transport in Taipei indeed own fewer cars after the establishment 
of Taipei MRT. In other words, the strategies that encourage people to use public transit can decrease the level of household car ownership. We use the LR test to compare the fit of model 5 and model 6 . The statistics of LR chi-square with 1 degree of freedom is 106.35 and significant. This result shows that Model 6 is better than Model 5. To compare the coefficients of area $\times M R T$ among Model 4, Model 5, and Model 6, the introduction of variables does not have a sizable impact on the treatment effect in term of magnitude. Hence, we can obtain the same conclusion that Taipei MRT is effective in controlling the level of car ownership.

\section{CONCLUSIONS}

This paper investigates whether the Taipei MRT system can effectively control the level of household car ownership. And, we analyse how demographic and socioeconomic characteristics determine the level of household car ownership. The household data is based on Taiwan's family income and expenditure survey from 1986 to 2006 including the period before and after the establishment of Taipei MRT. The full sample comprises 72800 households. We use the Poisson, generalized Poisson, and zero-inflated Poisson regression models. The difference-in-difference method was employed as a strategy to examine the effects of MRT.

The empirical results verify that the establishment of Taipei MRT significantly reduced the level of household car ownership. The effectiveness of this transportation policy can be attributed to the extension of Taipei MRT system and the improvement of service quality. The first line of Taipei MRT began operation in 1996. The length of Taipei MRT network has expanded from $10.5 \mathrm{~km}$ in 1996 to $115.6 \mathrm{~km}$ and ten lines in 2013. The average monthly total ridership of Taipei MRT has grown significantly from 1.1 million in 1996 to 54.9 million in 2012. The extension of Taipei MRT along with multiple bus lines constructs a well-developed public transport network and makes urban transport time-saving, efficient and clean. Thus, expanding the network of MRT system can be a feasible policy to control car ownership. Some strategies, such as enhancing the availability of transfer information and updating transit information timely, are helpful to move passengers efficiently and improve service quality. In addition, the Taipei MRT agency offers some discount policies to attract passengers. Thus, improving the quality of public transport services with a reasonable fare may not only encourage the use of public transport but also decrease the use of cars.

The Taipei MRT system has contributed to the improvement of public transport network. However, the increase in public transport use does not mean that the level of car ownership will decrease. We use the alternative specification to explore whether car users really switch to public transport and own fewer cars after the establishment of Taipei MRT. The evidence shows that households with high dependence on public transport own fewer cars after the establishment of Taipei MRT. In other words, the strategies that encourage people to use public transit can decrease the level of household car ownership. The results can clarify the determinants of household car ownership and highlight the importance of the MRT system for transportation planning and energy sustainability.

\section{ACKNOWLEDGEMENTS}

The research was sponsored by the National Science Council, Taiwan (NSC 101-2410-H-275 -010, NSC 102-2410-H-275-008). 


\section{REFERENCES}

1. Button, K., Ngoe, N. and Hine, J. L., Modelling vehicle ownership and use in low income countries, Journal of Transport Economics and Policy, Vol. 27, No. 1, pp. 51-67, 1993.

2. Dargay, J. and Gately, D., Income's effect on car and vehicle ownership, worldwide: 1960-2015, Transport Research Part A, Vol. 33, No. 2, pp. 101-138, 1999.

3. Abu-eisheh, S. A. and Mannering, F. L., Forecasting automobile demand for economies in transition: A dynamic simultaneous equation system approach, Transportation Planning and Technology, Vol. 25, No. 4, pp. 311-331, 2002., http://dx.doi.org/10.1080/0308106022000019026

4. Dargay, J. and Gately, D., Vehicle ownership to 2015 implications for energy use and emissions, Energy Policy, Vol. 25, pp. 1121-1127, 1997., http://dx.doi.org/10.1016/S0301-4215(97)00104-3

5. Pongthanaisawan, J. and Sorapipatana, C., Relationship between level of economic development and motorcycle and car ownerships and their impacts on fuel consumption and greenhouse gas emission in Thailand, Renewable and Sustainable Energy Reviews, Vol. 14, pp. 2966-2975, 2010., http://dx.doi.org/10.1016/j.rser.2010.07.034

6. Giuliano, G. and Dargay, J., Car ownership, travel and land use: a comparison of the US and Great Britain, Transportation Research Part A, Vol. 40, pp. 106-124, 2006., http://dx.doi.org/10.1016/j.tra.2005.03.002

7. Whelan, G., Modelling car ownership in Great Britain, Transport Research Part A, Vol. 41, No. 3, pp. 205-219, 2007.

8. Matas, A. and Raymond, J. L., Changes in the structure of car ownership in Spain, Transportation Research Part A, Vol. 42, pp 187-202, 2008., http://dx.doi.org/10.1016/j.tra.2007.08.005

9. Dargay, J. M., The effect of income on car ownership: Evidence of asymmetry, Transport Research Part A, Vol. 35, No. 9, pp 807-821, 2001.

10.Pongthanaisawan, J. and Sorapipatana, C., Relationship between level of economic development and motorcycle and car ownerships and their impacts on fuel consumption and greenhouse gas emission in Thailand, Renewable and Sustainable Energy Reviews, Vol. 14, pp. 2966-2975, 2010., http://dx.doi.org/10.1016/j.rser.2010.07.034

11.Nolan, A., A dynamic analysis of household car ownership, Transportation Research Part A, Vol. 44, pp. 446-455, 2010., http://dx.doi.org/10.1016/j.tra.2010.03.018

12.Dissanayake, D. and Morikawa, T., Investigating household vehicle ownership, mode choice and trip sharing decisions using a combined revealed preference/stated preference Nested Logit model: Case study in Bangkok Metropolitan Region, Journal of Transport Geography, Vol. 18, pp. 402-410, 2010., http://dx.doi.org/10.1016/j.jtrangeo.2009.07.003

13.Bhat, C.R. and Guo, J. Y., A comprehensive analysis of built environment characteristics on household residential choice and auto ownership levels, Transportation Research Part B, Vol. 41, pp. 506-526, 2007., http://dx.doi.org/10.1016/j.trb.2005.12.005

14.Nagai, Y., Okada, Y., Fukuda, A. and Hashino, Y., Two-wheeled vehicles ownership trends and issues in the Asian region, Journal of the Eastern Asia Society for Transportation Studies, Vol. 5, pp 135-146, 2003.

15.Matas, A., Raymond, J. L. and Roig, J. L., Car ownership and access to jobs in Spain, Transportation Research Part A, Vol. 43, pp. 607-617, 2009., http://dx.doi.org/10.1016/j.tra.2009.04.003

16.Cullinane, S., The relationship between car ownership and public transport provision: A case study of Hong Kong, Transport Policy, Vol. 9, pp. 29-39, 2002., http://dx.doi.org/10.1016/S0967-070X(01)00028-2 
17.Cullinane, S. and Cullinane, K., Car dependence in a public transport dominated city: Evidence from Hong Kong, Transportation Research Part D, Vol. 8, pp 129-138, 2003.

18.Chen, C.-F. and Lai, W.-T., The effects of rational and habitual factors on mode choice behaviors in a motorcycle-dependent region: Evidence from Taiwan, Transport Policy, Vol. 18, pp. 711-718, 2011., http://dx.doi.org/10.1016/j.tranpol.2011.01.006

19.Younes, B., The benefits of improving public transport: a myth or reality? Transport Reviews, Vol. 15, No. 4, pp. 333-356, 1995., http://dx.doi.org/10.1080/01441649508716924

20.Lai, W.T. and Lu, J. L., Modeling the working mode choice, ownership and usage of car and motorcycle in Taiwan, Journal of the Eastern Asia Society for Transportation Studies, Vol. 7, pp. 869-895, 2007.

21.Chang, H.L. and Wu, S. C., Exploring the vehicle dependence behind mode choice: Evidence of motorcycle dependence in Taipei, Transportation Research Part A, Vol. 42 , No. 2, pp. 307-320, 2008., http://dx.doi.org/10.1016/j.tra.2007.10.005

22.Consul, P. C. and Famoye, F., Generalized Poisson regression model, Communication in Statistics - Theory and Methods, Vol. 21, pp. 89-109, 1992.

23.Famoye, F., Restricted generalized Poisson regression model, Communications in Statistics, Theory and Methods, Vol. 22, pp. 1335-1354, 1993., http://dx.doi.org/10.1080/03610929308831089

24.Lambert, D., Zero-inflated Poisson regression, with an application to defects in manufacturing, Technometrics, Vol.34, No.1, pp. 1-14, 1992. http://dx.doi.org/10.2307/1269547

25.Vuong, Q. H., Likelihood ratio tests for model selection and non-nested hypotheses, Econometrica, Vol. 57, pp. 307-333, 1989., http://dx.doi.org/10.2307/1912557

26.Ashenfelter, O. and Card, D., Using the longitudinal structure of earnings to estimate the effect of training programs, Review of Economics and Statistics, Vol. 67, No. 4, pp. 648-660, 1985., http://dx.doi.org/10.2307/1924810

27.Card, D. and Krueger, A. B., Minimum wages and employment: A case study of the fast-food industry in New Jersey and Pennsylvania, American Economic Review, Vol. 84, No. 4, pp. 772-793, 1994.

28.Eissa, N. and Liebman, J. B., Labor supply response to the earned income tax credit, Quarterly Journal of Economics, Vol. 111, No. 2, pp. 605-637, 1996. http://dx.doi.org/10.2307/2946689

29.Finkelstein, A., The effect of tax subsidies to employer-provided supplementary health insurance: Evidence from Canada, Journal of Public Economics, Vol. 84, pp. 305-339, 2002., http://dx.doi.org/10.1016/S0047-2727(00)00155-9

30.Hardoy, I. and Schone, P., Incentives to work? The impact of a 'Cash-for-Care' benefit for immigrant and native mothers labour market participation, Labour Economics, Vol. 17, pp. 963-974, 2010., http://dx.doi.org/10.1016/j.labeco.2010.02.008

31.Strumpf, E., Medicaid's effect on single women's labor supply: Evidence from the introduction of Medicaid, Journal of Health Economics, Vol. 30, pp. 531-548, 2011., http://dx.doi.org/10.1016/j.jhealeco.2011.02.002

32.Li, H., Graham, D. J. and Majumdar, A., The effects of congestion charging on road traffic casualties: A causal analysis using difference-in-difference estimation, Accident Analysis and Prevention, Vol. 49, pp. 366-377, 2012., http://dx.doi.org/10.1016/j.aap.2012.02.013

33.Abadie, A., Semiparametric difference-in-difference estimators, Review of Economic Studies, Vol. 72, pp. 1-19, 2005., http://dx.doi.org/10.1111/0034-6527.00321

34.Potoglou, D. and Kanaroglou, P. S., Modelling car ownership in urban areas: a case study of Hamilton, Canada, Journal of Transport Geography, Vol. 16, pp 42-54, 2008., http://dx.doi.org/10.1016/j.jtrangeo.2007.01.006 
35.Jou, R. C., Huang, W. H., Wu, Y. C. and Chao, M.C., The asymmetric income effect on household vehicle ownership in Taiwan: A threshold cointegration approach, Transportation Research Part A, Vol. 46, pp. 696-706, 2012., http://dx.doi.org/10.1016/j.tra.2012.01.001

36.Hardin, J. W. and Hilbe, J. M., Generalized Linear Models and Extensions, Third Edition, Stata Press, 2012.

37.Redman. L., Friman, M., Garling, T. and Hartig, T., Quality attributes of public transport that attract car users: A research review, Transport Policy, Vol. 25, pp. 119-127, 2013., http://dx.doi.org/10.1016/j.tranpol.2012.11.005

38.Liao, P. A. and Taylor, J. E., Health care reform and farm women's off-farm labor force participation: Evidence from Taiwan, Journal of Agricultural and Resource Economics, Vol. 35, No.2, pp. 281-298, 2010. 